\title{
Avaliação e gestão da excelência na Pós-Graduação em Educação
}

\author{
Indira Alves França \\ Fundação Oswaldo Cruz \\ Alicia MariaCatalano de Bonamino \\ Pontifícia Universidade Católica do Rio de Janeiro
}

\section{Resumo}

Este artigo examina características da gestão de quatro Programas de PósGraduação em Educação considerados de excelência na avaliação da Capes. À luz de contribuições de Ball e Bourdieu analisa documentos oficiais e depoimentos de coordenadores, membros da ANPEd e do FORPREd e representantes da Area de Educação, revelando as estratégias desenvolvidas pelos representantes dessas instâncias para avançar, legitimar e consolidar suas posições nas hierarquias do campo da pós-graduação. Mais especificamente, revela convergências e divergências na forma de a gestão dos programas se relacionar com a avaliação da Capes, que envolvem a gestão coletiva, o credenciamento docente e a seleção de alunos e professores.

Palavras-chave: Pós-graduação em Educação. Gestão. Avaliaçãoda Capes.

\section{Evaluation and management of excellence in Posgraduate Education}

\section{Abstract}

This article examines management features of four Postgraduate Education Programs considered excellent by the evaluation system of Capes. In light of contributions from Ball and Bourdieu, it analyzes official documents and testimonies of coordinators, ANPEd and FORPREd members and representatives from the Educational Field, revealing the strategies developed by representatives of these bodies to advance, legitimize and consolidate their positions in the hierarchies of the postgraduate field. More specifically, it reveals convergences and divergences in the way the management of the programs relates to the evaluation of Capes, envolving collective management, the accreditation of teachers and the selection of students and teachers.

Keywords: Postgraduate. Management. Evaluation of the Capes. 


\section{Evaluacióny gestión de la excelencia en el Postgrado en Educación}

\section{Resumen}

En este artículo se examina la gestión de cuatro programas de posgrado en educación considerados de excelencia por la evaluación de la Capes. A partir de las contribuciones de Ball y de Bourdieu analiza documentos oficiales y entrevistas realizadas con coordinadores, miembros de ANPEd, FORPREd y representantes del Área de Educación, y revela las estrategias desarrolladas por los representantes de estas instancias para promover, legitimar y consolidar sus posiciones jerárquicas en el campo del posgrado. Trata específicamente de las convergencias y divergencias en la forma como la gestión de los programas se relaciona con la evaluación de la Capes, por medio de la gestión colectiva, la acreditación docente y la selección de estudiantes y profesores.

Palabras-clave: Posgrado. Gestión. Evaluación de la Capes.

\section{Introdução}

A Área de Educação é uma das que concentra o maior número de programas de pós-graduação stricto sensu, entre as 48 áreas de conhecimento da Coordenação de Aperfeiçoamento de Pessoal de Nível Superior (Capes). crescimento sustentado da oferta de cursos de mestrado e doutorado fez com que esse número praticamente triplicasse entre 2000 e 2014 , passando de 54 programas para 153. Nesse conjunto, 62 programas oferecem cursos de mestrado e doutorado, 62, apenas, o mestrado acadêmico e 29 o mestrado profissional.

No que se refere à distribuição das notas dos programas, verifica-se, na Avaliação Trienal 2013, uma maior concentração na nota 4 (41\%), seguida pela nota $3(38 \%)$ e pela nota $5(14 \%)$. Os programas com as notas mais altas, e considerados de excelência, estão concentrados nas Regiões Sudeste e Sul e constituem $7 \%$ do total, sendo $5 \%$ nota 6 , e $2 \%$ nota 7 .

tamanho da pós-graduação em Educação e a posição dos programas na avaliação trienal colocam em pauta o tema da gestão dos cursos de pós-graduação, cujo aperfeiçoamento é apontado pela Capes (2013) como um dos desafios para os próximos anos. 
A gestão de programas de pós-graduação e suas possíveis relações com o desempenho nas avaliações da Capes é o foco deste artigo, que aborda as características da gestão de quatro Programas de Pós-Graduação em Educação (PPGEd) considerados de excelência.

Além desta Introdução, o texto está estruturado em cinco seções. A próxima seçãoapresenta a estratégia utilizada na seleção dos programas investigados. A terceira seção aborda as contribuições teóricas de Stephen Ball e de Pierre Bourdieu, autores de referência da pesquisa. A quarta seção apresenta a análise da Pós-Graduação em Educação à luz dessas contribuições. Por fim, as conclusões encerram o artigo.

\section{A seleção dos programas de excelência}

Para a realização do estudo, foram selecionadas, no conjunto dos programas da área de Educação, aqueles que conseguiram avançar de nota duas vezes ao longo dos triênios de 2004, 2007 e 2010', passando a integrar o reduzido grupo de programas de excelência na Avaliação Trienal 2010. Foram quatro os programas que se encontravam nessa condição: da Pontifícia Universidade Católica do Rio Grande do Sul (PUCRS), da Universidade Estadual do Rio de Janeiro (Ueri), o Programa de Pós-Graduação em Conhecimento e Inclusão Social em Educação da Universidade Federal de Minas Gerais (UFMG) e o da Universidade do Vale do Rio dos Sinos (Unisinos). Os dois primeiros programas foram considerados nota 5 (cinco) na Avaliação Trienal 2001 (triênio 1998-2000) e chegaram à nota 7 (sete) em 2010 (triênio 20072009), enquanto os dois últimos, no mesmo período, foram considerados nota 4 (quatro) e chegaram à nota 6 (seis).

Na seleção, levou-se em consideração que o avanço em dois pontos na nota seria um indicativo de que esses programas teriam realizado transformações internas significativas envolvendo a coordenação, que estariam relacionadas com a melhora evidenciada nos resultados obtidos ao longo dos triênios estudados.

objetivo do estudo foi compreender como se caracteriza a relação entre a condição de excelência e a gestão em cada um desses quatro programas, com ênfase nas estratégias acionadas pelos seus coordenadores, entre 2001 e 2010, visando ao alcance dessa condição. 
Trata-se de programas que pertencem a instituições tradicionais de natureza diferenciada ${ }^{2}$. A Uerj e a UFMG são instituições públicas, sendo a primeira de âmbito estadual, e a segunda federal. A PUCRS e a Unisinos são instituições particulares, de caráter confessional e filantrópico.

Nesses programas, a pesquisa realizou quatro estudos de caso, por meio de análise documental e entrevistas semiestruturadas. A análise documental envolveu produções da Capes, relativas ao período de 1998 a 2014, a saber: Fichas de Avaliação dos Programas, Documentos de Área, Relatórios Síntese de Área, Cadernos de Indicadores e dados de acesso livre de cada avaliação trienal. Também foi feito um levantamento de documentos oficiais relativos à política de pós-graduação, o que inclui, entre outros, os Planos Nacionais de Pós-Graduação (PNPG). As entrevistas foram realizadas com 16 coordenadores que ocuparam o cargo no período de 2001 a 2013 e com membros da diretoria da Associação Nacional de Pós-Graduação e Pesquisa em Educação (ANPEd), do Fórum Nacional de Coordenadores de Programas de Pós-Graduação em Educação (FORPREd) e com representantes da Área de Educação na Capes, totalizando 20 entrevistas.

A elaboração dos roteiros das entrevistas e a análise dos documen128 tos e depoimentos foram realizadas à luz das contribuições teóricas de Pierre Bourdieu e dos aportes teórico-metodológicos de Stephen Ball.

\section{Contribuições de Stephen Ball e de Pierre Bourdieu ao estudo}

Oreferencial analítico do ciclo de políticas de Ball e colaboradores (BOWE; BALL; GOLD, 1992; BALL, 1994) permite superar visões reducionistas da política educacional, reescrevendo-a na análise das influências mútuas entre os contextos macro e micro. Ao enfatizar os processos micropolíticos e a ação dos profissionais emnível local, Ball lança luz sobre as possibilidades de intervenção e de mudança colocadas pelas interações entre o contexto global e o contexto local. Ball propõe a leitura das políticas como um ciclo contínuo, formado por três contextos inter-relacionados: de influência, de produção de texto e da prática.

No Contexto de Influência, as políticas são iniciadas, os discursos políticos são construídos e adquirem legitimidade. Nele, atuam redes sociais relacionadas a partidos políticos, aos governos, comissões e grupos 
representativos, que disputam a definição das finalidades da educação. No caso da política brasileira de pós-graduação, situam-se, nesse contexto, agências como a Capese órgãos de fomento à pesquisa, como o CNPq, comissões responsáveis pela elaboração das avaliações e do PNPG, representantes de programas e de associações nacionais de pesquisa de diferentes áreas de conhecimento, como a ANPEd e o FORPREd, no caso da Educação.

Ball também aponta a presença de influências internacionais na formulação das políticas nacionais, que se constituem a partir do fluxo que envolve: (a) a circulação internacional de ideias; (b) o processo de empréstimo de políticas; e (c) os grupos de indivíduos que vendem soluções no mercado político e acadêmico. No caso da pós-graduação, as influências internacionais se concretizam através da circulação de ideias entre acadêmicos (autores, professores, pesquisadores e discentes) e pela adoção de parâmetros científicos internacionais que definem e avaliam a qualidade das publicações científicas brasileiras.

Contexto de Produção de Texto das políticas se articula a textos com linguagem de interesse público mais geral, como a legislação, os textos políticos, comentários formais ou informais, pronunciamentos etc., que são fruto de disputas e acordos entre diferentes grupos de interesses. Nessa perspectiva, é importante identificar quais são os grupos de interesse representados/ excluídos, as vozes presentes/ausentes, a busca de consensos na construção do texto, as inconsistências e contradiçõesetc. $\bigcirc$ contexto de produção de texto évoltadopara as relações entre a Capes, a ANPEd e o FORPREd e para documentos específicos relativos à avaliação dos programas de pós-graduação e àqueles elaborados pelas Universidades e pelos PPGE visando à sua regulamentação.

No Contexto da Prática, é possível observar como a política foi recebida e colocada em ação, como os atores envolvidos interpretam os textos, as alterações e adaptações que fazem, as resistências individuais ou coletivas, e as contradições, conflitos e tensões. Nesse contexto, trata-se de averiguar como os coordenadores interpretaram os textos da política, quais seus pontos de vista, como trabalharam para atingir os parâmetros estabelecidos pela Capes, quais os focos de resistências e de conflitos.

Em 1994³, Ball acrescentou dois contextos ao referencial inicial o Contexto de Resultados ou Efeitos e o Contexto da Estratégia Política -, 
Avaliação e gestão da excelência na Pós-Graduação em Educação

sugerindo, posteriormente, (MAINARDES; MARCONDES, 2009) que o primeiro fosse incluído no Contexto da Práticae o segundo no Contexto de Influência.

Neste estudo, optou-sepor seguir a orientação do autor, focando a análise nos primeiros três contextos, sem deixar de abordar, no entanto, o contexto de resultados e os efeitos sobre os programas das injunções da política de avaliação da Capes.

Ball (2004) também desenvolve o tema da performatividade, uma forma de regulamentação que atua por meio de julgamentos, indicadores e comparações. A cultura da performatividade está inserida no contexto mais geral de transformações no papel do Estado, relativas aos serviços sociais, às instituições do setor público e aos cidadãos, e que afetam, também, o modo comoseentendemo profissionalismo, as relações de trabalho e as subjetividades. Para Ball, a performatividade é:

[...] uma tecnologia, uma cultura e um método de regulamentação que emprega julgamentos, comparações e demonstrações como meios de controle, atrito e mudança [...] alcançada mediante a construção e publicação de informações e de indicadores, além de outras realizações e materiais institucionais de caráter promocional, como mecanismos para estimular, julgar e comparar profissionais em termos de resultados: a tendência para nomear, diferenciar e classificar (BALL, 2005, p. 543).

No contexto dessa cultura, segundo Ball (2005), a gestão passa a visar, prioritariamente, ao desempenho, à qualidade e à eficácia, em detrimento das questões éticas, como a justiça social, a equidade e a tolerância e do debate sobre as consequências dessas novas práticas.

Para Ball, a definição de metas ambiciosas de perfeição e desempenho implica que pesquisadores e acadêmicos passem a serconsiderados produtores/fornecedores, que ficam sujeitos a julgamentos, mensurações, comparações de resultados e metas.

Um elemento importante é, para Ball, o papel de destaque que o gestor ocupa nesse contexto.

A figura central, o herói, no meio disto tudo, e o principal beneficiário da reforma, é um actor relativamente novo no palco das organizações do sector público - o gestor. O propósito da devolução [pagamento dos professores de acordo com desempenho], 
como refere a $\bigcirc \mathrm{CDE}$, é 'encorajar os gestores a centrarem a sua acção nos resultados, dando-lhes flexibilidade e autonomia no uso de recursos humanos e financeiros' (BALL, 2002, p. 6).

No caso dos programas de excelência, os coordenadores são chamados a traçar metas e a cuidar do desempenho dos seus programas, ao mesmo tempo que devem assumir a responsabilidade pelo gerenciamento dos recursos financeiros concedidos no âmbito do Programa de Excelência Acadêmica $(\text { Proex })^{4}$, levando em consideração os critérios e as orientações da Capes.

conceito de campo científico de Bourdieu, também foi uma referência fundamental para a pesquisa que deu origem a este artigo. Segundo Bourdieu (1983), o conceito designa o lugar da luta concorrencial pelo monopólio da competência científica, isto é, da capacidade de falar e de agir de maneira autorizada e com autoridade. Convenções desse campo fazem com que os julgamentos sobre a capacidade técnica de alguém estejam sempre perpassados pelo conhecimento da posição que essa pessoa ocupa nas hierarquias do campo. Em razão disso, as práticas científicas são orientadas para a aquisição de autoridade e não há escolha científica que não seja uma estratégia política de investimento objetivamente orientada para a maximização do lucro científico, no sentido do reconhecimento dos pares. Segundo o autor,

As transformações do campo científico baseiam-se na estrutura de distribuição do capital científico e se manifestam em estratégias de conservação e subversão dessa mesma estrutura. Nesse sentido, os investimentos dos pesquisadores dependem da importância do seu capital atual, do potencial de reconhecimento e de sua posição atual e potencial no campo, o que faz com que as ambições científicas sejam tanto mais altas, quanto mais elevado é o capital em termos de reconhecimento (BOURDIEU, 1983, p. 127).

A distribuição do capital científico ocorre por meio da luta pela legitimidade, entre agentes desigualmente dotados de capital específico, que opõe dominantes e dominados (novatos). Segundo Bourdieu (1983), os dominantes consagram-se as estratégias de conservação, visando à perpetuação da ordem científica. Essa ordem não se reduz à ciência oficial, mas abrange o conjunto das instituições encarregadas de assegurar a produção e a circulação dos bens científicos, bem como a circulação e a reprodução dos produtores e consumidores desses bens, ou seja, o sistema de ensino como um todo. 
Os dominados e os novatos, por sua vez, podem orientar-se por "estratégias de sucessão", mais seguras e previsíveis, dentro de limites autorizados, ou por "estratégias de subversão", mais arriscadas porque só asseguram lucros se houver mudanças que permitam uma redefinição completa dos princípios de legitimação da dominação.

Para Bourdieu, à medida que crescem os recursos científicos acumulados, eleva-se o grau de homogeneidade entre os concorrentes, e as estratégias de manutenção e subversão tendem a se enfraquecer.

Bourdieu (2004) classifica o capital científico em duas espécies: "capital científico puro", relativo a contribuições reconhecidas para o progresso da ciência (invenções, descobertas, publicações) e "capital científico institucional", adquirido por meio de estratégias políticas que exigem tempo de participação em bancas, comissões, colóquios, reuniões, a ocupação de cargos etc.

Para Bourdieu (2004), ao capital científico puro corresponde o poder específico do "prestígio" que repousa sobre o reconhecimento, pelo conjunto de pares, da produção científica do agente. Esse capital tem algo de impreciso, indeterminado e carismático porque está ligado a dons pessoais.

Já o capital científico institucionalizado refere-se ao poder institucional e institucionalizado, que resulta tanto da ocupação de posições importantes nas instituições científicas, direção de laboratórios ou departamentos, pertencimento a comissões, comitês de avaliação etc., como do poder sobre os meios de produção (contratos, créditos, postos) e de reprodução que ele assegura (poder de nomear e fazer carreira). Esse tipo de capital possui as mesmas formas de transmissão de qualquer capital burocrático e sua acumulação pode ocorrer por meio de nomeações, concursos, eleições.

De acordo com Bourdieu (2004), a acumulação das duas espécies de capital é extremamente difícil, porque requer investimentos diferentes e o tempo consumido na ocupação de cargos de gestão pode comprometer o tempo destinado à produção científica pelo pesquisador.

$\bigcirc$ meio acadêmico, no qual se inserem os programas de pós-graduação, é estruturado por hierarquias institucionais, lutas concorrenciais, distribuição desigual de capital científico e de poder. Nesse caso, Bourdieuchamaaatençãopara os coordenadores dos programas de excelência e suas estratégias de conservação, investimento, sucessão e acumulação de capital científico. 


\section{A Pós-Graduação em Educação: contextos e estratégias}

Os principais achados da pesquisa, apresentados a seguir, foram obtidos a partir do diálogo com o ciclo da política e com o conceito de performatividade de Ball e com o conceito de campo científico de Bourdieu.

\section{Contexto de influência e contexto de produção de texto}

Tendo como referência esses dois contextos, foi possível observar influências internacionais e nacionais reveladas na atual política de pós-graduação.

As influências internacionais na estrutura da pós-graduação brasileira têm raízes históricas. Verhine (2008) argumenta que o modelo brasileiro de pós-graduação é híbrido, expressão de um ajuste entre características do modelo americano (profissional) e do modelo europeu (tutorial) às particularidades da educação brasileira.

Ao longo das décadas de 1980 e 1990, no âmbito político e econômico mundial, ocorreram mudanças, como a diminuição das fronteiras nacionais, o crescimento de conglomerados econômicos e da competitividade tecnológica, que levaram as instituições de ensino superior (IES) a enfatizar a produção em Ciência, Tecnologia e Inovação (CT\&l).

Em particular, as mudanças no processo de avaliação de programas de pós-graduação pela Capes, ao longo da década de 1990, acompanharam a importância mundial dada aos investimentos em CT\&l. Nessa perspectiva, definiu-se um novo modelo de avaliação centrado na pesquisa e na produção científica, com vistas ao estabelecimento da qualidade dos cursos e à alocação de recursos financeiros de acordo com as notas obtidas pelos programas nas avaliações trienais (HORTA; MORAES, 2005). Entrevistado por haverocupado o cargo de coordenador da Área de Educação na Capesentre 2004 e 2006, o professor Robert Verhine lembra outras iniciativas da política brasileira de pós-graduação que sintonizam tendências internacionais. Entre elas, conta-se o mestrado profissional promovido nos anos 90, bem como a ênfase na pesquisa, na inovação, na busca de padrões internacionais de excelência e no intercâmbio entre docentes e discentes do país e do exterior.Segundo o "Relatório de Avaliação 2010-2012/Trienal 2013",

Os principais indicadores de tal excelência são a produção científica veiculada tanto em periódicos indexados quanto em livros 
- principal forma de expressão da produção da área no âmbito nacional e internacional; a participação em redes institucionais de pesquisa; intercâmbio de docentes e discentes; o potencial de formação de pesquisadores com perfil compatível com os dos centros de excelência no exterior; a capacidade de nucleação de atividades de pesquisa nas áreas do programa; e a inserção social (BRASIL, 2013, p. 39).

A classificação dos periódicos feita pelo Sistema Qualis transformou-se em outra das dimensões da influência internacional na pós-graduação brasileira. $\bigcirc$ Qualis reúne títulos de periódicos utilizados pelos programas de pós-graduação para a divulgação da produção intelectual de seus docentes e alunos. Em razão disso, o Qualis se tornou, a partir de 2001, uma referência para a avaliação e qualificação da produção científica nacional e um importante parâmetro na definição do sentido da excelência segundo padrões internacionais para os programas de pós-graduação (PINTO; CUNHA, 2008).

Esse ponto conduz ao interior do campo científico da pós-graduação brasileira e às lutas que ali se travam, entre diferentes áreas de conhecimento e pelos programas, em torno da acumulação e da conservação do capital 134 científico. Um primeiro nível de disputa pela hegemonia do campo científico confronta o domínio das Áreas das Ciências Exatas e Naturais com as Ciências Humanas e Sociais. A própria Capes, no texto do PNPG 20 10-2020, reconhece que: "Historicamente, houve a hegemonia ou a predominância de critérios, culturas e procedimentos das Ciências Exatas e Naturais, as quais migraram para outras áreas e funcionaram como uma camisa de força" (BRASIL, 2010, p. 127).

Outra evidência objetiva dessa hegemonia é que os programas das Áreas das Ciências Humanas e Sociais têm prioridade menor na distribuição de bolsas Capes. De fato, o artigo $4^{\circ}$ do Regulamento de Apoio à Pós-Graduação (Proap) ${ }^{5}$ define que o valor de referência para alocação de recursos financeiros para cada programa de pós-graduação é fixado em função da disponibilidade orçamentária da Capese da cota de bolsas Demanda Social (DS), de acordo com o peso da natureza da área do conhecimento e nível de formação (mestrado ou doutorado). $\bigcirc$ quadro de pesos apresentado no regulamento mostra que, enquanto Ciências Exatas e da Terra, Ciências Biológicas, Engenharias, Ciências da Saúde e Ciências Agrárias têm peso 4 para mestrado e 5 para doutorado; Ciências Sociais Aplicadas, Ciências 
Humanas e Letras e Linguística têm peso 2 para o mestrado e 3 para o doutorado.

O dirigente do FORPREd, inclusive, mencionou durante a entrevista que uma das lutas junto à Capes é no sentido de que Educação passe a ser considerada "prioridade um" na distribuição de bolsas e recursos.

Ainda segundo Bourdieu (1983), no campo científico, a hierarquia é sustentada também pelos níveis de legitimidade concedidos aos produtos científicos. Nesse sentido, outro nível em que se expressa a hegemonia das Ciências Exatas e Naturais, na avaliação da Capes é o da valorização do artigo científico em detrimento do livro. $\bigcirc$ artigo é um produto legitimado nas Ciências Exatas e Naturais, e a generalização da sua legitimidade para as Ciências Humanas e Sociais, cujo produto mais característico é o livro, revela outra dimensão da capacidade de determinadas áreas para hegemonizar uma definição da ciência compatível com o que elas "têm, são e fazem".

Em relação a essas influências, os agentes entrevistados pela pesquisa, deforma geral, demonstraram ter consciência de que a Área da Educação ainda precisa posicionar melhor suas especificidades no campo científico.

Em outro nível do Contexto de Influência,constatou-se a força da Capes na determinação da política de pós-graduação, que se reflete claramente no Contexto de Produção de Texto. De forma geral, os coordenadores afirmaram que os Documentos de Área da Educação e a Ficha de Avaliação dos Programas, elaborados pela Capes, compreendem os textos que acabam por interferir mais diretamente em suas atividades de coordenação. Esses textos estabelecem os parâmetros e as metas que orientam a ação dos programas, à luz dos quais eles são avaliados periodicamente para determinação de sua "posição" nas hierarquias do campo da pós-graduação.

Desde o I Plano Nacional de Pós-Graduação - PNPG (1975-1979), a Capesavalia os cursos de pós-graduação. O processo iniciou-se, em 1976, com o objetivo de gerar parâmetros para a distribuição de bolsas de estudo. Em busca de uma avaliação mais distintiva e com parâmetros mais objetivos, conforme ocorria internacionalmente, a Capes estabeleceu um novo paradigma de avaliação, na década de 1990. Esse novo modelo mudou o ciclo avaliativo de bianual para trienal, preservou a autoridade dos comitês (avaliação por pares) e adotou um conjunto mais objetivo de indicadores e regras. 
A partir da reformulação do sistema de avaliação, os conceitos básicos que caracterizam o nível de desempenho dos programas passaram a ser expressos por notas que variam de 3 a 7 . Para a determinação dos conceitos dos programas, atualmente são avaliados os seguintes quesitos: Proposta do Programa; Corpo Docente; Corpo Discente, Teses e Dissertações; Produção Intelectual; e Inserção Social. De acordo com os resultados obtidos nesses quesitos, são conferidas notas e conceitos: "5" (Muito Bom), "4" (Bom) e "3" (Regular). A nota "3" é o mínimo a ser atingido por um programa para ser oficialmente reconhecido.

Os programas com notas "6" e "7" (Programas de Excelência) são aqueles enquadrados como conceito " 5 " pela segunda vez na avaliação trienal e que, em uma segunda rodada de avaliação, apresentam desempenhos equivalentes aos dos centros internacionais de excelência e nível de desempenho altamente diferenciado em relação aos demais programas (BRASIL, 2013). Os que atingem esse patamar passam a participar do Programa de Excelência Acadêmica (PROEX) e recebem uma dotação orçamentária maior, que pode ser utilizada de acordo com as suas prioridades, desde que respeitada a meta anual mínima de destinação de 50\% dos recursos de custeio para bolsas de 136 estudo (Programa de Excelência Acadêmica - PROEX) (BRASIL, 2006).

A nova avaliação impactou fortemente a Área da Educação no biênio 1996-1997, levando ao descredenciamento de vários cursos de mestrado. Esse episódio mobilizou os programas da área, o FORPREd e os participantes da $21^{a}$ Reunião Anual da ANPEd, em 1998, quando foi elaborado um documento que discutia o modelo de avaliação e propunha alternativas.

No triênio seguinte, em 2001, algumas alterações foram introduzidas pela Capes; dentre elas, está o papel assumido pelo CTC da Capes, que passou de órgão encarregado da homologação dos resultados dosprogramasatribuídos pelas comissões de área para assumir o questionamento dessas avaliações, chegando mesmo a modificar os conceitos atribuídos pelas comissões de área aos programas ${ }^{6}$.

Isto significou, para aqueles que participam ativamente do processo?, a disputa entre uma avaliação feita pelas comissões de pares, que leva em consideração as especificidades das áreas e programas, e o CTC, que homogeneíza a avaliação com base nos critérios das áreas hegemônicas, como as Ciências Exatas e da Terra e as Ciências Biológicas. Evidência disso é o 
resultado da avaliação trienal 2001, que mostra uma forte concentração dos programas com conceito 7 (sete) nessas duas grandes Áreas (61,2\%), emboraelascomportassem apenas $21,6 \%$ dos programas avaliados. Em contrapartida, dos 29 programas que tiveram seus conceitos 7 (sete) e 6 (seis) rebaixados, 15 deles (52\%) eram da Grande Área de Ciências Humanas (GACH), especialmente Educação e Geografia, que somaram 12 programas ou $41 \%$ do total de cursos rebaixados.

Como parte do que sepode entender como "estratégias de subversão" das regras que pautam as hierarquias do campo científico da pós-graduação, no triênio 2004, a Área da Educação e a GACH, especialmente a Geografia, travaram um embate com as Áreas de Ciências Exatas e Naturais com vistas a ter seus critérios e especificidades assegurados nas Fichas de Avaliação. A GACH se articulou para estabelecer critérios de avaliação dos cursos 6 e 7, assentando-os no tripé: a) formação, b) corpo docente e c) pesquisa e produção científica com inserção internacional. Além disso, buscou alianças com representantes das Áreas de Ciências Sociais Aplicadas, Letras e Linguística e Música e Artes, visando à construção de critérios comuns, o que resultou numa reunião do grupo que se denominou Grande Área de Humanidades. $\bigcirc$ relatório dessa reunião estabeleceu o entendimento do nível de excelência dos programas de humanidades e apontou o lugar central que os livros deveriam ocupar na avaliação dos programas da Área, por constituírem uma forma apropriada de expressão e divulgação de seus produtos científicos (HORTA; MORAES, 2005).

No ano de 2004, no processo de avaliação dos programas no triênio, foi realizada a elaboração do Qualis/Eventos, do Qualis/Periódicos e dos critérios de recomendação de livros para a Área de Educação. A partir de então, houve a inclusão de livros e de capítulos de livros na avaliação da produção intelectual dos programas da Área. Ainda em 2004, a GACH especificou os critérios para a Qualificação de produção bibliográfica e artística de excelência.

A Avaliação Trienal dos cursos na Capes é desenvolvida pelos comitês de área, formados por consultores acadêmicos escolhidos dentre profissionais de comprovada competência em pesquisa e ensino de pós-graduação. Embora com uma autonomia restrita, esses comitês são responsáveis por parte dos critérios e diretrizes dessa avaliação e pela sua divulgação em documentos próprios de cada área. Entre suas atribuições, compete aos comitês 
a qualificação da produção científica pelo Sistema Qualis em cada área de pesquisa.

Criado em 2001 para classificar a produção bibliográfica (principalmente periódicos) dos programas de pós-graduação em todas as áreas de conhecimento, o sistema passou a ser um importante parâmetro nas avaliações trienais. A base de dados Qualis é referência para avaliação da produção científica nacional e reúne, apenas, os títulos de periódicos utilizados pelos programas de pós-graduação para adivulgação da produção intelectual de seus docentes e alunos. Esse instrumento orienta a comunidade universitária a buscar um padrão de excelência para os cursos stricto sensu (PINTO; CUNHA, 2008).

Inicialmente, os periódicos, e parte da produção bibliográfica brasileira eram classificados em três níveis (A, B ou C) e pelo tipo de circulação (internacional, nacional ou local). Uma mudança na classificação ocorrev em 2008, quando a Capes criou uma nova escala Qualis para a produção acadêmica no Brasil, contendo oito estratos: A1, A2, B1, B2, B3, B4, B5 e C. Em cada estrato, a produção bibliográfica possui um número de pontos diferenciado, de forma tal que, quanto mais próximo de $A$, maior a pontuação 138 dos periódicos, sendo Al a melhor classificação e C a pior. Na Área da Educação, os periódicos classificados como C, não contam ponto. Essa nova classificação permitiu à Capes a criação de um número maior de estratos, uma maior discriminação da produção acadêmica e a redução do número de periódicos classificados nos níveis mais altos (A 1 e A2) (ANDRIOLO;BARBOSA; HERNANDEZ; CAMARGOS; BARRAVIEIRA; KANDUC, 2010).

A análise das fichas de avaliação utilizadas pela nossa área nas cinco últimas avaliações trienais (de 2001 a 2013) revela que a mobilização da Área da Educação em conjunto com a GACH e no âmbito do Comitê Técnico Científico (CTC) provocaram mudanças no peso dos quesitos que compõem a avaliação dos programas. Essas alterações estão mostradas no Quadro 1. 


\section{Quadro 1}

\section{Evolução dos quesitos das Fichas de Avaliação da Área da Educação nas Avaliações Trienais (2001 a 2013)}

\begin{tabular}{|c|c|c|c|c|c|}
\hline \multirow{2}{*}{ Quesitos } & \multicolumn{5}{|c|}{ Pesos dos Quesitos } \\
\cline { 2 - 6 } & 2001 & 2004 & 2007 & 2010 & 2013 \\
\hline Proposta do Programa & 0 & 0 & 0 & 0 & 0 \\
\hline Corpo Docente & 15 & 15 & 30 & 15 & 15 \\
\hline Atividade de Pesquisa & 20 & 20 & & & \\
\hline Atividade de Formação & 15 & 15 & & & \\
\hline Corpo Discente & 10 & 10 & 30 & 35 & 35 \\
\hline Teses e Dissertações & 20 & 20 & & 35 & 35 \\
\hline Produção Intelectual & 20 & 20 & 30 & 35 & 35 \\
\hline Inserção Social & & & 10 & 15 & 15 \\
\hline Soma dos Pesos & 100 & 100 & 100 & 100 & 100 \\
\hline
\end{tabular}

Fonte | Capes-2004 | Documentos de Área (2001 a 2013)

Como pode ser observado, os quesitos "Atividade de Pesquisa" e "Atividade de Formação" passaram a fazer parte do quesito Corpo Docente, que teve seu peso relativamente diminuído. Isso contrasta com o aumento do peso de quesitos como Produção Intelectual e Corpo Discente, Teses e Dissertações que juntos passam a corresponder a 70\% da avaliação do programa e a conformar o fator de maior impacto numa avaliação que considera o artigo o principal produto da pós-graduação.

Por outro lado, houve a inclusão de peso no quesito Inserção Social do Programa o que, juntoàconsideração de livros e capítulos como produtos intelectuais dos programas, são evidências concretas das conquistas da Área de Educação e da GACH no campo da pós-graduação.

\section{Contexto da Prática}

contexto da prática é aquele no qual a política está sujeita à interpretação e recriação, e o que produz efeitos e consequências que podem representar mudanças e transformações significativas na política original (BOWE; BALL; GOLD, 1992). Ao analisar as experiências dos quatro programas 
Avaliação e gestão da excelência na Pós-Graduação em Educação

de excelência selecionados pela pesquisa, procurou-se entender como as injunções dos contextos de influência e de produção de textos da política brasileira de pós-graduação foram interpretadas e traduzidas em ação, no Contexto da Prática.

Os programas de pós-graduação estudados representam a arena em que a política é colocada em ação e os sujeitos dessa ação são os coordenadores que atuaram no períodoquando houve a mudança nas notas dos programas. Nessa perspectiva, buscou-se compreender as interpretações que fazem da política proposta, as estratégias que adotam para traduzir essa política em ação e as semelhanças e diferenças que ensejam suas ações, organizando a análise do Contexto da Prática a partir de dois temas: a) relação dos coordenadores com a avaliação da Capes; b) estratégias de ação dos programas.

\section{a) Relação dos coordenadores com a avaliação da Capes}

A avaliação da Capes afeta diretamente o cotidiano dos programas e, principalmente, o trabalho do coordenador, agente mediador entre as injunções do processo de avaliação e as traduções da política de pós-graduação junto ao e com o corpo docente e discente do programa. Embora no Documento de Área e no Relatório da Avaliação Trienal, a excelência esteja estreitamente relacionada à divulgação da produção intelectual em veículos emnível internacional, os agentes apontam suas próprias interpretações sobre o que torna um programa "de excelência". Para eles, a excelência existe porque o programa foi fundado por acadêmicos reconhecidos, ou porque desenvolve uma política de internacionalização que não se preocupa apenas com os grandes centros acadêmicos, e oferta doutorados em Angola ou em países latino-americanos, ou porque seus docentes possuem uma compreensão própria da qualidade, que enfatiza a docência e o trabalho na graduação.

Em que pese essas "estratégias de subversão" da ordem dominante, todos os coordenadores, sem exceção, apresentaram argumentos em favor da avaliação da Capes. A maior parte deles afirma que a qualidade atual da pós-graduação brasileira é consequência da avaliação realizada pela Capes. No entendimento desses agentes, o processo de avaliação propiciou a melhoria da qualidade da pesquisa, especialmente na Área da Educação. Esse também é o entendimento do dirigente do FORPREd entrevistado na pesquisa, para 
quem "Deve-se considerar que, de modo geral, a avaliação busca salvaguardar a qualidade da pós-graduação. A intenção é boa" (DIRIGENTE FORPRED, 2013).

Alguns coordenadores destacaram que o processo tem credibilidade pelo fato de ser feito por pares e que a avaliação da Capes culminou, favorecendo, também, o desenvolvimento da pesquisa em programas de instituições particulares que, sem a mediação da avaliação, tenderiam a focar suas atividades, apenas, no ensino.

A maior parte dos coordenadores entrevistados acha positiva a associação entre mérito e fomento e considera que a avaliação proporciona um uso mais racional e adequado do dinheiro público.

De acordo com o dirigente da ANPEd entrevistado:

[...] você não pode distribuir recursos públicos sem saber se eles serão destinados para fonte segura, que os objetivos serão realizados. Isso a gente obtém por meio da avaliação. Então, a avaliação é um mecanismo importante para garantir isso (DIRIGENTE ANPEd, 2013).

A forma adotada no financiamento dos programas, entretanto, não é consenso entre os coordenadores. Parte deles alega que pode causar uma injusta divisão dos recursos públicos, na medida em que acaba por favorecer programas e instituições mais estruturados, que conseguem atingir os critérios de qualidade com mais facilidade.

dirigente do FORPREd também abordou esse aspecto em sua análise do sistema de avaliação da Capes. Para ele,

[...] esse é um fator de aumento da desigualdade regional e institucional dos programas de pós-graduação. Aqueles que estão em Universidades menores, em Universidades com menos recursos, tendem a ser penalizados e a avançarem com muita dificuldade. Os que estão em regiões mais privilegiadas economicamente e em Universidades com mais recursos, tendem a avançar e conseguir mais recursos, mais reconhecimento. Há uma espécie de dualidade estrutural que está ligada à região geográfica, ao prestígio acadêmico, aos recursos econômicos (DIRIGENTE FORPREd, 2013 ). 
Emuma perspectiva similar, um dos coordenadores da Área da Educação (CA-Edu A) lembrou que a própria Capese o Conselho Nacional de Desenvolvimento Científico e Tecnológico (CNPq) promovem programas e editais dirigidos, prioritariamente, a regiões e temas específicos, visando minimizar as desigualdades.

Então a questão do mérito acadêmico está muito clara. No entanto, "você" não pode esquecer que existem outros programas que contemplam projetos de outras Instituições, de outras entidades que tiveram dificuldades. Então, todos os alunos de todos os programas de pós-graduação da região Norte tem bolsa. Não é pela qualidade só, mas são outros elementos. Há vários editais de fomento do CNPq só para a Região Norte, Nordeste e Centro-Oeste. Então, na área, de fato, elas estão relacionadas, mas existem vários programas de fomento: "[...] só ganha quem tiver [...] há projetos, inclusive, em que se você não estiver filiado ao grupo de alguma Universidade do Norte-Nordeste você não ganha. Então, tem esses projetos de fomento, também" (CA-EDU A, 2013).

Outra categoria que aparece recorrentemente nas críticas dos coordenadores ao processo de avaliação da Capesé o produtivismo, especialmente nos programas das universidades particulares. Em contrapartida, os coordena-

142 dores dos programas das IES públicas argumentam que não há produtivismo na Área da Educação, visto que, para eles, as exigências quantitativas e qualitativas de produção docente anual podem ser tranquilamente atingidas.

Os coordenadores acreditam que as críticas ao produtivismodecorrem da sobrecarga de trabalho a que estão submetidos os docentes nas IES. Do ponto de vista da gestão, de fato, as atividades têm se tornado cada vez mais complexas, pois envolvem cuidar, simultaneamente, da avaliação, da produção intelectual do programa e de sua internacionalização, da pesquisa e seus recursos, da formação dos alunos, dos prazos, dos recursos financeiros, além de outras atividades administrativas do programa e da Universidade. Em razão disso, parte expressiva dos coordenadores percebe que o tempo dedicado à gestão acaba por prejudicar sua pesquisa e sua produção intelectual.

Em face dessas colocações, foram questionados os motivos que levariam os professores a aceitar a coordenação do programa. A despeito das dificuldades relatadas, as entrevistas com os coordenadores também apontam para a importância do valor simbólico do cargo, pela visibilidade, o poder e as oportunidades de articulação política que sua ocupação viabiliza. 


\section{b) Estratégias de ação dos programas}

Foi possivel depreender das entrevistas que os coordenadores reelaboram as orientações estabelecidasemnível macro de forma diferenciada, de acordo com suas interpretações subjetivas e com suas experiências institucionais e coletivas. Em decorrência disso, escolhem diferentes estratégias para a execução da Política de Pós-Graduação e para sua "tradução" em ações no Contexto da Prática. Os quatro programas adotaram estratégias similares em relação a três dimensões, a saber: a gestão coletiva dos programas, o corpo docente e o corpo discente.

A gestão coletiva dos programas se refere a um conjunto de características que faz com que as decisões mais importantes da gestão sejam compartilhadas por uma equipe de professores. Os dezesseis coordenadores entrevistados demonstraram estarapoiados no trabalho por um grupo de professores que divide com eles a responsabilidade pela gestão do programa.

Os textos da política de pós-graduação da Capespreveem iniciativas de gestão coletiva, como o Regulamento do Proex 8 (Programa de Excelência Acadêmica - Proex (BRASIL, 2006), que indica a necessidade de os programas instituírem uma Comissão de Gestão - CG/Proex, com a atribuição de aprovar o Plano de Metas Acadêmicas e de servir de instância de acompanhamento e julgamento de questões relativas às verbas recebidas.

Entretanto, nos documentos da Capes, há uma ênfase na centralização da gestão na figura do coordenador, deixando a seu cargo a maior parte das responsabilidades administrativas, financeiras e jurídicas, em termos da prestação de contas e de suas responsabilidades no atendimento às normas operacionais do Proex.

A despeito disso, em todas as experiências analisadas, a centralização é minimizada por estratégias de gestão coletiva, que estão baseadas em um tripé comum, constituído por um núcleo docente forte de tomada de decisão, um colegiado atuante, e comissões permanentes e temporárias para apoio às diferentes tarefas do processo de gestão. Também foi abordado o tema das mudanças introduzidas no perfil docente dos programas pelo processo acelerado de aposentadorias nas instituições públicas, seguido de um "êxodo" para instituições privadas e pelo início de um processo de renovação docente em cada um dos programas. Foi interessante perceber que os novos professores que ingressaram nos programas tinham uma perspectiva de atuação mais 
Avaliação e gestão da excelência na Pós-Graduação em Educação

alinhada com os critérios de avaliação estabelecidos pela Capes, em termos de pesquisa, de publicação e de internacionalização, o que favoreceu o início das mudanças realizadas ao longo da década de 2000.

Há tensões nessas relações, principalmente no alinhamento dos docentes mais antigos com o que a Capesespera em termos de produtividade. A forma de equacionamento desta questão em todos os programas estudados tem sido a renovação paulatina do quadro docente, com processo seletivo direcionado a um novo perfil de professor, com maior volume de produção científica.

Ademais,é importante mencionar que, no caso das IES públicas pesquisadas, ao contrário das privadas, as alterações no corpo docente, ao longo da década, resultaram na ampliação do quadro de professores ${ }^{9}$. No caso, os programas de universidades particulares chegaram à última avaliação trienal com uma média um pouco menor de docentes do que no início da década ${ }^{10}$.

Os quatro programas adotaram uma política de credenciamento docente, que inclui processos de descredenciamento. Esse é um ponto de convergência importante entre as experiências. No caso das IES públicas, os professores da pós-graduação, em geral, já faziam parte do quadro docente da instituição, com atuação no âmbito da graduação, e sua entrada nos programas passou a ocorrer de maneira mais formalizada e mediada pelo compromisso com a produção acadêmica.

Já a entrada de professores novos para o quadro docente dos programas das instituições privadas ocorreu por meio de processo seletivo direcionado para a pós-graduação, que envolveu o posterior acompanhamento sistemático da produção intelectual dos novos professores.

Se os quatro programas investigados adotaram processos rigorosos de credenciamento e descredenciamento, nas universidades privadaso descredenciamento teve um impacto maior na vida do programa e dos docentes, uma vez que colocou em causa a demissão de professores.

conjunto decoordenadores, que parece concordar com as regras de credenciamento existentes em seus programas, defendendo-as com entusiasmo em diferentes momentos das entrevistas, também deixa claro que são processos que criam um forte conflito ético. São processos baseados na cultura da performatividade (BALL, 2005) e que envolvem uma sobrecarga de trabalho e o estresse que suas consequências causam em seus colegas e neles próprios. 
Diante disso, alguns entrevistados advertem que cabe ao coordenador de Programa ter bom senso, no sentido de não pressionar demais a equipe em razão das metas de produção. Segundo Ball,

Tanto as interações quanto as relações de colegas e de professores e alunos são potencialmente retrabalhadas. No que se refere às interações, existem pressões sobre os indivíduos, formalizadas por meio de avaliações, revisões anuais e bancos de dados, para que deem sua contribuição à performatividade da unidade. Aí reside uma possibilidade concreta de que as relações sociais autênticas sejam substituídas por relações performativas, em que as pessoas são valorizadas com base exclusivamente na sua produtividade (BALL, 2005, p. 556).

Nessa perspectiva, os gestores tambémse referem a ações realizadas pela coordenação do programa, no sentido de apoiar os professores na melhoria de sua produção. Entre essas ações, destacam-se as informações sobre os veículos qualificados para publicação e sobre editais específicos aos quais os professores podem concorrer na busca de recursos.

Ao lado da produção intelectual docente, outro fator de impacto na avaliação da pós-graduação é a produção intelectual discente, que passou a ser mais valorizada quando realizadajunto aos docentes do programa. Para garantir os tempos de titulação e a produção dos discentes, os programas tomaram medidas que envolvem formas de seleção dos alunos aos cursos de mestrado e doutorado com base na sintonia com os projetos de pesquisa dos docentes. Se esse é um expediente comum nas áreas das Ciências Exatas e Naturais, ainda é contestado na Área da Educação, com exceção dos programas da Unisinos e da Ueri, em que essa modalidade parece ser mais hegemônica e estar consolidada.

Da mesma forma, a coordenação da maioria dos programas passou a realizar um acompanhamento mais atento do desempenho acadêmico dos alunos e a instituir estratégias visando ao aumento da publicação discente como, por exemplo, a exigência de publicação acadêmica como requisito parcial para a conclusão do curso. 


\section{Contexto dos efeitos}

A análise dos efeitos decorrentes da chancela de excelência recebida pelos programas está circunscrita à percepção dos coordenadores sobre suas consequências materiais e simbólicas. $\bigcirc$ aumento dos recursos financeiros foi mencionado por todos os coordenadores entrevistados como uma consequência da conquista da "excelência" na avaliação da Capes. Isto porque essa condição implica o repasse diferenciado de recursos a programas que tenham obtido conceito 6 ou 7 em duas avaliações consecutivas da Capes, sendo que esse reconhecimento teria propiciado, também, o aumento dos recursos auferidos pelos programas junto a outras agências de fomento.

Para os coordenadores, os ganhos simbólicos gerados pela conquista da excelência parecem ser tão importantes quanto os ganhos financeiros. Em primeiro lugar, os coordenadores mencionam que ser um programa de excelência significou um maior reconhecimento dentro das próprias instituições, implicando mudanças significativas em relação à autonomia institucional e às condições de trabalho.

Esse reconhecimento fez com que mais docentes e discentes passas146 sem a querer fazer parte dos programas de excelência, o que contribuiu para a melhoria de sua qualidade, pois ampliou as possibilidades de seleção, tornando possível a escolha de melhores candidatos para os quadros docente e discente.

Na outra face da moeda, outro efeito concreto da excelência e do reconhecimento foi a sobrecarga de trabalho a que ficaram expostos docentes e coordenadores. Nos últimos triênios, houve a redução de tempo de formação, que foi acompanhada pela ampliação da proporção de discentes por docente permanente e pelo aumento da produção qualificada docente e discente. Além disso, novas demandas foram encetadas aos programas, seja pela necessidade de atingir e manter níveis de produção considerados de padrão internacional, seja pelas propostas de parcerias e de apoio a outros programas (MINTER, DINTER e PROCAD/Casadinhos), ou, ainda, pelo aumento da responsabilidade dos coordenadores em relação aos recursos do PROEX. 


\section{Conclusões}

A pós-graduação brasileira, lócus principal da pesquisa e da produção de conhecimento, conforma, com suas especificidades, o campo científico, numa perspectiva pautada pela cultura da performatividade. Segundo Bourdieu (1983), para garantir as melhores posições nas hierarquias do campo científico, diferentes agentes travam uma luta concorrencial, mobilizam determinados capitais e lançam mão de estratégias específicas. Com esta pesquisa, foi possível analisar as posições diferenciadas e as estratégias acionadas nesse campo por representantes da Área de Educação e pelos coordenadores de programas considerados de excelência.

Nas hierarquias do campo científico, o maior prestígio e o poder acadêmico das Ciências Exatas e Naturais ficaram evidenciados na prioridade dessas áreas, em relação às Ciências Humanas e Sociais, para aceder à distribuição de bolsas e recursos da Capes. Por ocupar a posição mais alta nas hierarquias do campo científico, as Ciências Exatas e Naturais também detêm a capacidade de definir a forma legítima de se fazer ciência.

Ademais, os coordenadores de programas de excelência sustentaram, nas entrevistas, que a lógica da pesquisa das Ciências Exatas e Naturais, cujos produtos são divulgados como maior facilidade em função da legitimidade do conhecimento que produzem, se contrapõe ao modo de fazer ciência na Área das Ciências Humanas e, especificamente, na Área da Educação, revelando ter consciência de que a nossa Área ainda precisa posicionar melhor suas especificidades no campo científico.

Os níveis de legitimidade concedidos aos produtos científicos (BOURDIEU, 1983) também sustentam o posicionamento diferenciado das áreas de conhecimento nas hierarquias do campo. No caso da pós-graduação, cabem à Avaliação da Capes e ao Sistema Qualis a definição de regras e critérios que embasam essa hierarquia. Trata-se de regras e de critérios pautados nas áreas dominantes que privilegiam a divulgação da pesquisa no formato artigo, produto característico das Ciências Exatas e Naturais. Da prioridade dada ao artigo classificado nos estratos mais altos do Qualis, decorre a luta bem-sucedida da Área da Educação e de Ciências Humanas para legitimar o livro, como forma específica de divulgação do conhecimento produzido nessas áreas e como produto científico junto à Capes. 
Também foi possível identificar "estratégias de sucessão" (BOURDIEU, 1983) acionadas pelos coordenadores da Área de Educação e dos programas de excelência estudados. No conjunto dessas estratégias, encontra-se a legitimidade que a maioria desses coordenadores confere às regras hegemônicas das Ciências Exatas e Naturais quando reconhece o papel positivo da Avaliação da Capes na regulação da pesquisa e do "jogo" científico e como fator de melhoria da qualidade da pós-graduação no país.

Os coordenadores em geral aprovam a avaliação conduzida pela Capes, reconhecendo sua contribuição para a legitimação da pós-graduação no Brasil, em especial, para a legitimação da pesquisa da Área da Educação junto à comunidade acadêmica. Argumentam sobre os pontos positivos da avaliação, considerando que ela é feita por pares, que garante um uso mais racional e adequado do dinheiro público e um incentivo à pesquisa, especialmente em programas de instituições particulares, tradicionalmente mais voltadas para o ensino.

Com base nessas apreciações, a maior parte dos entrevistados rebate as críticas de outros representantes da Área da Educação que entendem ser o modelo de avaliação da Capes homogeneizador e produtivista. $\bigcirc$ grupo 148 defende as exigências da avaliação em relação à quantidade e à qualificação das publicações docentes e não vê como negativa a generalização dos critérios das Ciências Exatas e Naturais, que reconhece como sendo as áreas mais consolidadas no campo científico.

A Educação é considerada uma Área cujo desenvolvimento tardio como campo de investigação científica teria consequências que são sentidas até os dias atuais. Prova disso, de acordo com os coordenadores entrevistados, é o fato de a Área da Educação só ter atingido a nota 7 na Avaliação Trienal 2010, além de ter, em comparação e em proporção às outras Áreas dentro da Capes, um número reduzido de programas considerados de excelência.

produtivismo é outro tema recorrente e que divide posições entre os coordenadores dos programas estudados. Há, entre os coordenadores, das universidades particulares, a percepção de que a Capes impõe parâmetros de avaliação tão exigentes em termos de publicações qualificadas, que acabam por desrespeitar o tempo próprio da pesquisa e da produção intelectual da Educação. Em contrapartida, os coordenadores dos programas de universidades públicas argumentam que não há produtivismo na Ârea de Educação e 
na Capes, considerando as exigências de publicação adequadas e fáceis de atender.

Os coordenadores tendem a reconhecer, no entanto, que assumir as atribuições da coordenação acaba interferindo na acumulação de capital científico (BOURDIEU, 2004), porque afeta suas atividades de pesquisa, além de ocupá-los em uma tarefa que demanda tempo para ser cumprida.

alinhamento do modelo de avaliação da Capes com a racionalidade das Ciências Exatas e Naturais e da visão dos coordenadores dos programas de excelência com esse modelo está relacionado à cultura da performatividade e envolve aspectos como comparação, padronização, aferição de resultados e recompensas (BALL, 2002).

Na pós-graduação brasileira, em particular, essa cultura implica o estabelecimento de "metas" a serem alcançadas. A "devolução" do desempenho atingido pelos Programas em relação às metas propostas é materializada pela Avaliação da Capes, que define hierarquias entre os programas através das notas. Os programas mais produtivos e eficientes recebem a chancela de "Programa de Excelência", obtêm mais recursos financeiros da Capes e um maior reconhecimento da comunidade científica.

Visando à manutenção da posição de excelência conquistada, os coordenadores adotam estratégias de gestão em comum, direcionadas, especialmente, aos corpos docente e discente e à gestão coletiva, que estão em consonância com os parâmetros de Avaliação da Capes.

A principal estratégia relacionada aos professores é a política de credenciamento, que inclui o acompanhamento sistemático de sua atuação e produção visando à sua permanência no programa (recredenciamento). $\bigcirc$ descredenciamento é também uma medida adotada pelos programas pesquisados como alternativa para os docentes que não conseguem atingir as metas de produção intelectual, o que chegou a ocorrer em três dos quatro programas pesquisados (PUCRS, UFMG e Unisinos).

$\bigcirc$ credenciamento de docentes se mostra como um dos pontos mais emblemáticos da performatividade, na medida em que reflete uma nova ética baseada no interesse institucional, no pragmatismo e no valor performativo dos indivíduos.

Da necessidade de incrementar a produção intelectual, que não foi acompanhada de forma proporcional pelo crescimento do corpo docente, 
derivou uma sobrecarga de trabalho para coordenadores e professores. Os docentes tiveram que produzir mais e assumir novas atribuições e demandas decorrentes do fato de terem se tornado Programas de Excelência. Essas demandas se refletem numa maior "auto" cobrança, na multiplicação de pesquisadores e instituições que propõem parcerias, no aumento das tarefas designadas aos coordenadores, como a divulgação da experiência em outros programas, a administração dos recursos do Proex e o preenchimento do Coleta Capes.

As questões éticas implicadas no modelo também se revelam nas falas dos entrevistados, que se questionam tanto sobre o ritmo de trabalho que precisam manter e imprimir aos programas que coordenam para conseguir atingir as metas de produção acadêmica, como sobre suas consequências no plano da subjetividade docente. Nas entrevistas, os coordenadores revelaram enfrentar dilemas morais e emocionais no cotidiano dos seus programas, como formas de resistência à cultura da performatividade. Trata-se de questionamentos éticos que alguns deles encetam a sua própria prática profissional, que, em muitos casos se expressam no cuidado evidenciado na abordagem dos docentes sem produção.

Outro ponto de convergência na gestão dos programas de excelência diz respeito aos alunos. Trata-se do incentivo à publicação discente, de um maior rigor com o tempo de titulação ede mudanças no processo seletivo de candidatos ao mestrado e doutorado que incluem, como pré-requisito, a apresentação de projetos sintonizados com os objetos e temas das pesquisas desenvolvidas pelos docentes do programa.

Por sua vez, as estratégias de gestão coletiva emergiram como uma categoria nativa nos programas analisados. A gestão coletiva diz respeito a experiências de gestão compartilhadas, que fazem com que os coordenadores se sintam mais seguros e menos solitários na realização das tarefas. Essas experiências, em particular, indicam que as estratégias utilizadas pelos agentes podem se constituir não apenas a partir de ações de concorrência e competição, mas também de ações de cooperação com vistas ao alcance de metas coletivas.

Um dos aspectosreferentes aos ganhos simbólicos de pertencer a um Programa de excelência se relaciona com a aceitação do cargo de coordenador. Sem benefícios financeiros correspondentes à sobrecarga de trabalho 
gerada pela função, e com prejuízos para as atividades de docência e pesquisa, a visibilidade gerada pelo cargo acaba pesando positivamente para sua aceitação. Quando explicam os motivos e as vantagens que percebem nessa função, o valor simbólico do cargo sobressai na forma de uma maior visibilidade acadêmicae dasoportunidades de articulação política.

programa considerado de excelência passa a ser visto como uma referência. $\bigcirc$ reconhecimento da autoridade desses programas ficou evidenciado nas falas dos entrevistados, quando mencionam que o fato de terem se tornado Programas de Excelência "abriu portas" dentro e fora de suas instituições.

Ao passar a fazer parte do seleto grupo dos programas de excelência, eles ingressam em um círculo virtuoso que envolve uma melhor avaliação, melhores condições materiais, mais recursos financeiros, melhores possibilidades de seleção de docentes e discentes, mais e melhores produtos, o que, por sua vez, resulta na obtenção das melhores notas na Avaliação da Capes.

Há necessidade também de registrar a identificação pela pesquisa de formas de resistência à cultura da performatividade, que passam por uma reinterpretação ativa da política pelos programas. Isso pode percebido no entendimento que os coordenadores têm do que seja um Programa de Excelência: eles se mostram cientes da definição que a Capes confere a essa expressão sem, no entanto, deixar de manifestar e de operar um entendimento próprio. Nessa pauta, são valorizados aspectos como a tradição do programa e do corpo docente, o vínculo com movimentos sociais, a internacionalização, a solidariedade e o apoio a países menos desenvolvidos, o compromisso com a docência na graduação, os valores relacionados ao trabalho coletivo e, ainda, o trabalho com a comunidade local.

Em um contexto de performatividade, hegemonizado pela racionalidade técnica, com critérios de qualidade fechados e totalizantes, como os definidos no âmbito da Avaliação da Capes, os sujeitos correm o risco de se tornar "meros expectadores" de suas práticas (BALL, 2005). Entretanto, ao explicitarem suas próprias convicções do que seja um Programa de Excelência e, principalmente, ao buscar agir de acordo com elas, esses profissionais conseguem constituir-se como "sujeitos da ação", que realizam uma gestão mais coletiva e apoiada na reflexão sobre a prática. 


\section{Notas}

1 De acordo com a Avaliação da Capes, os programas de pós-graduação podem ser classificados com nota 3 (regulares), nota 4 (bons) e nota 5 (muito bons). Os programas com conceito 5 são submetidos a uma nova rodada de avaliação para ser classificados como nota 6 ou 7 (Programas de Excelência). Estas últimas são as notas concedidas, especialmente no caso da nota 7, a programas que, além de forte liderança nacional, apresentam um diferencial no seu desempenho, especialmente em termos de produção intelectual e de formação de recursos humanos comparáveis às de centros internacionais de excelência.

2 Os cursos de mestrado da UFMG, da Ueri, da PUCRS e da Unisinos foram iniciados, respectivamente, em 1965, 1972, 1972 e 1994.

3 BALL, S. J. Educational reform: a critical and post-structural approach.Buckingham: Open University Press, 1994.

4 Programa de Excelência Acadêmica (Proex) tem como objetivo manter o padrão de qualidade dos programas de pós-graduação com nota 6 ou 7, por meio de um financiamento diferenciado a um número restrito e exclusivo de programas, podendo comportar, no máximo, até $7 \%$ do total de programas reconhecidos pela Capes. O Proex abrange 15\% do orçamento da Capes destinado a bolsas e ações de fomento na pós-graduação.

5 Portaria n64, de 24 de março de 2010.

6 Ao final do processo da avaliação do triênio 1998-2001, dos 1545 programas avaliados pelas comissões de área, 41 deles tiveram seus conceitos rebaixados pelo CTC (sendo que 76\% deles situavam-se na faixa dos conceitos 6 e 7) e 3 tiveram seus conceitos aumentados.

7 José Silvério Baía Horta foi representante da Área da Educação no período 1999-200 1 e representante da Grande Área de Ciências Humanas (GACH) no CTC (2000-2001) e, no triênio seguinte, como membro da comissão de avaliação. Maria Célia Marcondes de Moraes foi representante adjunta (1999-2001) e representante de Área (2002-2004).

8 Portaria $n^{\circ} 34$, de 30 de maio de 2006.

9 A média de docentes permanentes na Uerj e UFMG era, respectivamente, de 19 e 33 no Triênio 2004 e de, respectivamente, 24 e 59 no triênio 2010.

10 A média de docentes permanentes na PUCRS e Unisinos era de 15 no triênio 2004 e de, respectivamente, 13 e 14 no triênio 2010.

\section{Referências}

ANDRIOLO, Adagmar; BARBOSA, Alfredo José Afonso; HERNANDEZ, Arnaldo José; CAMARGOS, Aroldo Camargos; BARRAVIEIRA, Benedito; KANDUC, Victoria.Classificação dos periódicos no Sistema Qualis da Capes - a mudança de critérios é URGENTE! Revista

Brasileira de Reumatologia, São Paulo, v. 50, n. 2, p. 107-1 12, 2010. 
BALL, Stephen J. Educational reform: a critical and post-structural approach.Buckingham: Open University Press, 1994.

BALL, Stephen. Reformar escolas/reformar professores e os terrores da performatividade. Revista Portuguesa de Educação, Braga, v. 15, n. 2, p. 3-23, semestral, 2002. Disponível em: <http://www.redalyc.org/articulo.oa?id=37415201>. Acesso em: 16 jan. 2014.

BALL, Stephen. Performatividade, privatização e o pós-Estado do bem-estar. Educação \& Sociedade, Campinas, v. 25, n. 89, p. 1 105-1126, 2004.

BALL, Stephen. Profissionalismo, gerencialismo e performatividade. Cadernos de Pesquisa, São Paulo, v. 35, n. 126, p. 539-564, set./dez. 2005.

BOURDIEU, Pierre. Os usos sociais da ciência: por uma sociologia clínica do campo científico. Tradução Denice Barbara Catani. São Paulo: Editora UNESP, 2004.

BOWE, Richard; BALL, Stephen; GOLD, A. With. Reforming education \& changing schools: case studies in policy sociology. London: Routledge, 1992.

BRASIL. Ministério da Educação. Plano Nacional de Pós-Graduação - PNPG 201 1/2020. Coordenação de Aperfeiçoamento de Pessoal de Nível Superior. Brasília: Capes, 2010.

Coordenação de Aperfeiçoamento de Pessoal de Nível Superior. Ministério da Educação. Programa de Excelência Acadêmica - Proex. Portaria $\mathbf{n}^{\circ} \mathbf{3 4}$, de $\mathbf{3 0}$ de maio 2006. Brasília: Capes, 2006.

Coordenação de Aperfeiçoamento de Pessoal de Nível Superior. Ministério da Educação. Avaliação Trienal 2001 (triênio 1998/ 2000) - Comissão de Área da Educação. Brasília: Capes, 2001.

Coordenação de Aperfeiçoamento de Pessoal de Nível Superior. Ministério da Educação. Programa de Excelência Acadêmica - Proex. Avaliação Trienal 2004 (triênio 2001/2003) - Comissão de Área da Educação. Brasília: Capes,2004.

Coordenação de Aperfeiçoamento de Pessoal de Nível Superior. Ministério da Educação. Programa de Excelência Acadêmica - Proex. Avaliação Trienal 2007 (triênio 2004/2006) - Comissão de Área da Educação. Brasília: Capes, 2007.

Coordenação de Aperfeiçoamento de Pessoal de Nível Superior. Ministério da Educação. Programa de Excelência Acadêmica - Proex. Avaliação Trienal 2010 (triênio 2007 /2009) - Comissão de Área da Educação. Brasília: Capes, 2010. 
Coordenação de Aperfeiçoamento de Pessoal de Nível Superior. Ministério da Educação. Programa de Excelência Acadêmica - Proex. Avaliação Trienal 2013 (triênio 2010/2012) - Comissão de Área da Educação. Braślia: Capes,2013.

Coordenação de Aperfeiçoamento de Pessoal de Nível Superior. Ministério da Educação. Programa de Excelência Acadêmica - Proex. Relatório de Avaliação Trienal 2013 (triênio 2010/2012) - Comissão de Área da Educação, Braślia: Capes,20 $13 b$.

CA-EDU A. Entrevista. São Paulo, 13 mar. 2013.

DIRIGENTE ANPEd. Entrevista. Rio de Janeiro, 16 maio. 2013.

DIRIGENTE FORPREd. Entrevista. Rio de Janeiro, 13 jul. 2013.

HORTA, José Silvério Baía; MORAES, Maria Célia Marcondes de. O Sistema CAPES de Avaliação da Pós-Graduação: da Área de Educação à Grande Área de Ciências Humanas.

Revista Brasileira de Educação, Rio de Janeiro, n. 30, p. 95-1 16, set./dez.2005.

MAINARDES, Jefferson. Abordagem do ciclo de políticas: uma contribuição para análise de políticas educacionais. Educação \& Sociedade, Campinas, v. 27, n. 94, p. 47-69, jan./ abr. 2006.

154 MAINARDES, Jefferson; MARCONDES, Maria Inês. Entrevista com Stephen J. Ball: um diálogo sobre justiça social, pesquisa e política educacional. Educação \& Sociedade, Campinas, v. 30, n. 106, p. 303-318, jan./abr. 2009.

PINTO, AngelodaCunha; CUNHA, Andréa Souza da. Avaliação da pós-graduação da área de química na Capes. Química Nova, São Paulo, v. 31 , n. 8, p. 2221 1-2226, 2008.

VERHINE, Robert. Pós-graduação no Brasil e nos Estados Unidos: uma análise comparativa. Educação, Porto Alegre, v. 31 , n. 2, p. 166-172, maio/ago. 2008.

Profa. Dra. Indira Alves França Fundação Oswaldo Cruz Instituto de Informação e Comunicação em Saúde Vice-Diretoria de Pesquisa, Ensino e Desenvolvimento Tecnológico Laboratório de Avaliação da Educação | LAEd E-mail | indira@icict.fiocruz.br 
Profa. Dra. Alicia Maria Catalano de Bonamino

Pontifícia Universidade Católica do Rio de Janeiro Departamento de Educação Programa de Pós-Graduação em Educação | PUC-Rio Laboratório de Avaliação da Educação | LAEd E-mail | alicia@puc-rio.br Recebido 15 ago. 2014 Aceito 17 nov. 2014 